\title{
INFLUÊNCIA DA POSIÇÃO E FORMATO DE CORTE NA PREFERÊNCIA SENSORIAL DE ABACAXI 'PÉROLA' MINIMAMENTE PROCESSADO'
}

\author{
LUCIMARA ROGÉRIA ANTONIOLLI², BENEDITO CARLOS BENEDETTI ${ }^{3}$, \\ MEN DE SÁ MOREIRA DE SOUZA FILHO ${ }^{4}$, DEBORAH DOS SANTOS GARRUTI ${ }^{5}$
}

\begin{abstract}
RESUMO - Procurou-se determinar a melhor porção do fruto, quanto aos teores de sólidos solúveis (SS) e acidez titulável (AT) e sua preferência sensorial, a ser destinada ao processamento mínimo, bem como o formato de corte preferido para a comercialização na forma de minimamente processado. Os frutos foram descascados manualmente, delimitados em 12 seções de $1 \mathrm{~cm}$ e fatiados, avaliando-se, cada fatia, quanto ao teor de SS e AT. O delineamento experimental foi em blocos casualizados, onde o fator estudado foi a seção do fruto, com quatro repetições. Os dados foram submetidos à análise de variância e as médias, comparadas pelo teste de Tukey. Sensorialmente, avaliou-se a porção do fruto de maior preferência, utilizando-se, para tanto, do teste de "Ordenação-Preferência". Os resultados foram analisados pelo teste não-paramétrico de Friedman. Os frutos foram ainda avaliados quanto ao formato de corte preferido, através do teste de "Preferência-Pareada". Considerando os teores de SS e AT, não haveria restrições quanto à total utilização do fruto; no entanto, sensorialmente, a porção delimitada pelos 3 centímetros apicais foi pouco aceita, sugerindo que a porção compreendida entre a $4^{\mathrm{a}}$ e a $12^{\mathrm{a}}$ seções seja preferencialmente utilizada no processamento mínimo. O corte do abacaxi no formato de fatias foi preferido ao formato em cubos.
\end{abstract}

Termos para indexação: Ananas comosus, sólidos solúveis, acidez titulável, preferência sensorial, formato de corte.

\section{INFLUENCE OF THE POSITION AND CUT SHAPE IN THE SENSORIAL PREFERENCE OF FRESH-CUT 'PÉROLA' PINEAPPLE}

\begin{abstract}
The purpose of this research was to determine the best portion of pineapple fruit to be used as fresh-cut considering soluble solids (SS), titratable acidity (TA) content and preference, as well as the preferred cut shape for its commercialization. Fruits were manually peeled, delimited in 12 sections of $1 \mathrm{~cm}$ and sliced. Each slice was evaluated for the SS and TA content. The experimental design was in randomized blocks. The studied factor was the fruit section, with four replicates. The data were submitted to the variance analysis and compared by Tukey's test. The preferred fruit portion was evaluated by "Ranking Preference" test, and the results were analyzed by Friedman's test. Fruits were also evaluated for cut shape by "Paired Preference" test. Considering the SS and TA values no restrictions were found for the total use of the fruit, however the portion delimited by the apical $3 \mathrm{~cm}$ was little accepted, suggesting that the portion between the $4^{\text {th }}$ and $12^{\text {th }}$ sections should be used in the minimum processing. Pineapple cut in slices was preferred to cubes.
\end{abstract}

Index terms: Ananas comosus, soluble solids, titratable acidity content, sensorial preference, cut shape.

A produção mundial de abacaxi está estimada em 12,8 milhões de toneladas, equivalente a $3 \%$ da produção mundial de frutas. O Brasil é o $2^{\circ}$ maior produtor de abacaxi, suplantado somente pela Tailândia (Usberti Filho et al., 1999). De acordo com dados do AGRIANUAL (2005), a produção de abacaxi durante o ano de 2003 foi de 2.890 .600 toneladas. A região Sudeste destaca-se como a principal produtora, seguida pelas regiões Nordeste e Norte. Os principais Estados produtores são Minas Gerais, Paraíba e Pará, sendo que o Estado de São Paulo ocupa o $4^{\circ}$ lugar.

O abacaxi apresenta excelente qualidade sensorial decorrente do sabor e aroma característicos que lhe são atribuídos por diversos constituintes químicos, como os açúcares, os ácidos, os ésteres, os carotenóides e demais constituintes vitamínicos, aminoácidos e protéicos (Botrel \& Patto de Abreu, 1994).

A acidez do abacaxi é devida, principalmente, aos ácidos cítrico e málico, que contribuem, respectivamente, com 80 e $20 \%$ da acidez total (Dull, 1971). No interior do fruto, a acidez aumenta da região basal para a apical, acompanhando o gradiente de maturação. Observa-se que a acidez é muito mais acentuada na região próxima à casca quando comparada à do cilindro central (Botrel \& Patto de Abreu, 1994; Reinhardt et al., 2003). De acordo com Smith (1988), abacaxis destinados ao consumo in natura devem apresentar teor de sólidos solúveis igual ou superior a 14\%; no entanto, Kader (1999) afirma que o teor mínimo de $12 \%$ de sólidos solúveis e o máximo de $1 \%$ de acidez titulável garantem aceitabilidade mínima pela maioria dos consumidores.

As principais cultivares de abacaxi exploradas em todo o mundo são: Smooth Cayenne, Singapore Spanish, Queen, Red Spanish, Pérola e Perolena, sendo que as cultivares Smooth Cayenne e Pérola lideram o mercado brasileiro (Gonçalves, 2000). Embora a grande maioria dos estudos realizados com alimentos minimamente processados esteja relacionada aos produtos hortícolas, constata-se o grande potencial de comercialização de frutas minimamente processadas, principalmente aquelas que oferecem, em função de sua própria estrutura, alguma dificuldade para comercialização ou até mesmo para consumo. Siriphanich \& Johnson (1994) destacaram o potencial do abacaxi ao descreverem o processamento mínimo de frutas tropicais.

O objetivo deste trabalho foi determinar a melhor porção do fruto a ser destinada ao processamento mínimo, bem como o formato de corte preferido para a sua comercialização, por meio de métodos estatístico-sensoriais de preferência.

Abacaxis (Ananas comosus (L.) Merril) cv. Pérola, provenientes de Touros-RN, foram transportados para o Laboratório de Fisiologia e Tecnologia Pós-Colheita da Embrapa Agroindústria Tropical, Fortaleza$\mathrm{CE}$, onde foram padronizados quanto ao tamanho e à coloração da casca (verde-pintado).

Os frutos foram medidos quanto à massa de matéria fresca $(\mathrm{kg})$, comprimento $(\mathrm{cm})$ e diâmetro $(\mathrm{cm})$ da maior seção transversal antes e após as operações de descoroamento e descascamento manual, com a finalidade de se determinar o rendimento do processo. Em seguida, os frutos foram delimitados transversalmente em 12 seções de $1 \mathrm{~cm}$ e fatiados a partir da região apical. As fatias foram numeradas, atribuindo-se 1 ao ápice e 12 à base, e tiveram o cilindro central removido.

As características químicas avaliadas foram: teor de sólidos solúveis ( ${ }^{\circ}$ Brix), determinado por refratometria (Atago PR-101) e acidez titulável (\% ácido cítrico), determinada através da diluição de $1 \mathrm{~g}$ de amostra homogeneizada em $50 \mathrm{~mL}$ de água destilada, e posterior titulação

\footnotetext{
${ }^{1}$ (Trabalho 039/2005). Recebido: 04/03/2005. Aceito para publicação: 17/11/2005. Apoio Financeiro: FAPESP; PRODETAB / BANCO MUNDIAL.

2 EMBRAPA UVA E VINHO. Caixa Postal 130, CEP 95700-000, Bento Gonçalves-RS. E-mail: lucimara@cnpuv.embrapa.br.

${ }^{3}$ FEAGRI / UNICAMP - Caixa Postal 6011, CEP 13083-970, Campinas-SP. E-mail: benedeti@agr.unicamp.br.

${ }^{4}$ EMBRAPA AGROINDÚSTRIA TROPICAL, Caixa Postal 13761, CEP 60511-110, Fortaleza-CE. E-mail: sa@cnpat.embrapa.br.

${ }^{5}$ EMBRAPA AGROINDÚSTRIA TROPICAL, Caixa Postal 13761, CEP 60511-110, Fortaleza-CE. E-mail: deborah@enpat.embrapa.br.
} 
automática com solução de $\mathrm{NaOH}$ 0,1N, até pH 8,10 (Mettler Toledo DL 12). Adotou-se o delineamento em blocos casualizados, onde o fator estudado foi a seção do fruto (12 seções), com quatro blocos compostos por cinco frutos. Cada bloco foi avaliado em um determinado dia, de forma que todos os blocos foram avaliados em 4 dias consecutivos. Os dados foram submetidos à análise de variância, sendo as médias comparadas pelo teste de Tukey, a $5 \%$ de probabilidade.

Sensorialmente, avaliou-se a porção do fruto de maior preferência. Para tanto, utilizou-se do teste de "Ordenação-Preferência" com a colaboração de 30 julgadores não treinados. Frutos com tamanho entre 12 e $15 \mathrm{~cm}$ foram descascados e delimitados em 4 porções de $3 \mathrm{~cm}$, sendo, cada uma delas, dividida radialmente em 8 pedaços iguais. A cada provador foram oferecidos, simultaneamente, 2 pedaços de cada uma das quatro porções do fruto, acondicionados em pratos plásticos devidamente codificados com números de três dígitos, sendo solicitado que ordenassem as amostras em ordem crescente de preferência. Foram atribuídas as ordens 1 e 4 às amostras de menor e maior preferência, respectivamente. Os resultados foram analisados através do teste de Friedman (Tabela de Newell e Mac Farlane), conforme sugerido por Ferreira et al. (2000).

Os frutos foram ainda avaliados quanto ao formato de corte por meio do teste de "Preferência-Pareada". Fatias de aproximadamente $1 \mathrm{~cm}$, sem cilindro central, e cubos, obtidos a partir do corte das fatias em 4 seções iguais, foram acondicionados em embalagens de polietileno tereftalato e em pratos plásticos devidamente codificados, de forma a simular o produto nos pontos de venda, no primeiro caso, e, no segundo, para eliminar a possível interferência da embalagem na preferência do julgador. Ambos os formatos de corte foram apresentados simultaneamente a cada um dos julgadores, aos quais foi solicitado que indicassem sua preferência. Os resultados foram analisados pela distribuição de $\chi^{2}$, utilizando a tabela de significância para o teste pareado bicaudal, ao nível de $5 \%$ de probabilidade, compilada por Roessler et al. (1978), apresentada no trabalho de Ferreira et al. (2000).

O rendimento do processamento foi de $59,03 \%$, considerando a massa inicial do fruto com coroa. O diâmetro e o comprimento pósdescascamento foram reduzidos a 92,34 e 91,19\% dos valores iniciais, respectivamente (dados não apresentados). Sarzi et al. (2002) obtiveram rendimento de $61,84 \pm 1,07 \%$ no processamento manual de abacaxis 'Pérola'.

Constatou-se um aumento no teor de sólidos solúveis em função do distanciamento da região apical do fruto (Figura 1A). Os teores, que variaram de $13,80^{\circ} \mathrm{Brix}$ no $1^{\circ}$ centímetro apical, a $17,88^{\circ} \mathrm{Brix}$ na última seção basal do fruto, foram muito superiores aos valores verificados em estudos preliminares conduzidos com abacaxis 'Pérola' provenientes do Estado do Tocantins (10,92 a 13,12 ${ }^{\circ}$ Brix, observados na $1^{\mathrm{a}}$ e na $17^{\mathrm{a}}$ seções, respectivamente). Usberti Filho et al. (1999) citaram teores de 10,$4 ; 11,8$ e 13,4 $4^{\circ}$ Brix, para as regiões apical, mediana e basal do fruto, respectivamente. $O$ teor de $0,89 \%$ de ácido cítrico, verificado na $1^{\mathrm{a}}$ seção apical do fruto, foi reduzido a $0,76 \%$ na $2^{\mathrm{a}}$ seção $\left(2^{\circ} \mathrm{cm}\right)$, sofrendo suaves reduções em função do distanciamento da região apical e atingindo o teor de $0,59 \%$ de ácido cítrico na última seção basal do fruto (Figura 1B). Os resultados obtidos foram superiores aos observados preliminarmente em frutos da mesma cultivar $(0,65$ e $0,43 \%$ de ácido cítrico para a $1^{\mathrm{a}}$ e a $17^{\mathrm{a}}$ seções, respectivamente). Usberti Filho et al. (1999) citaram valores de 0,67 e 0,57\% de ácido cítrico para as regiões apical e basal do fruto, respectivamente. É possível que os maiores valores de SS e AT observados neste experimento sejam decorrentes das diferentes condições edafoclimáticas de cultivo, uma vez que a temperatura e a disponibilidade de água exercem grande efeito sobre o desenvolvimento e a qualidade dos frutos.

Comparando as porções do fruto testadas e considerando os seguintes fatores: número total de julgamentos (30), número de amostras testadas (4), diferença mínima entre os totais de ordenação para se estabelecer diferença de preferência significativa entre as amostras, a $5 \%$ de significância (26), constatou-se que a porção basal $\left(10^{\mathrm{a}}\right.$ a $12^{\mathrm{a}}$ seções) foi a preferida pelos provadores; no entanto, não foi observada diferença significativa entre esta porção do fruto e a imediatamente superior a ela ( $7^{\mathrm{a}}$ a $9^{\mathrm{a}}$ seções). A porção menos aceita foi a equivalente aos 3 primeiros centímetros apicais, sem, no entanto, diferir significativamente da região compreendida pela $4^{\mathrm{a}}, 5^{\mathrm{a}}$ e $6^{\mathrm{a}}$ seções. Não foi observada diferença significativa entre as duas porções medianas do fruto ( $4^{\mathrm{a}}$ a $6^{\mathrm{a}}$ e $7^{\mathrm{a}}$ a $9^{\mathrm{a}}$ seções) (Figura $\left.2 \mathrm{~A}\right)$.
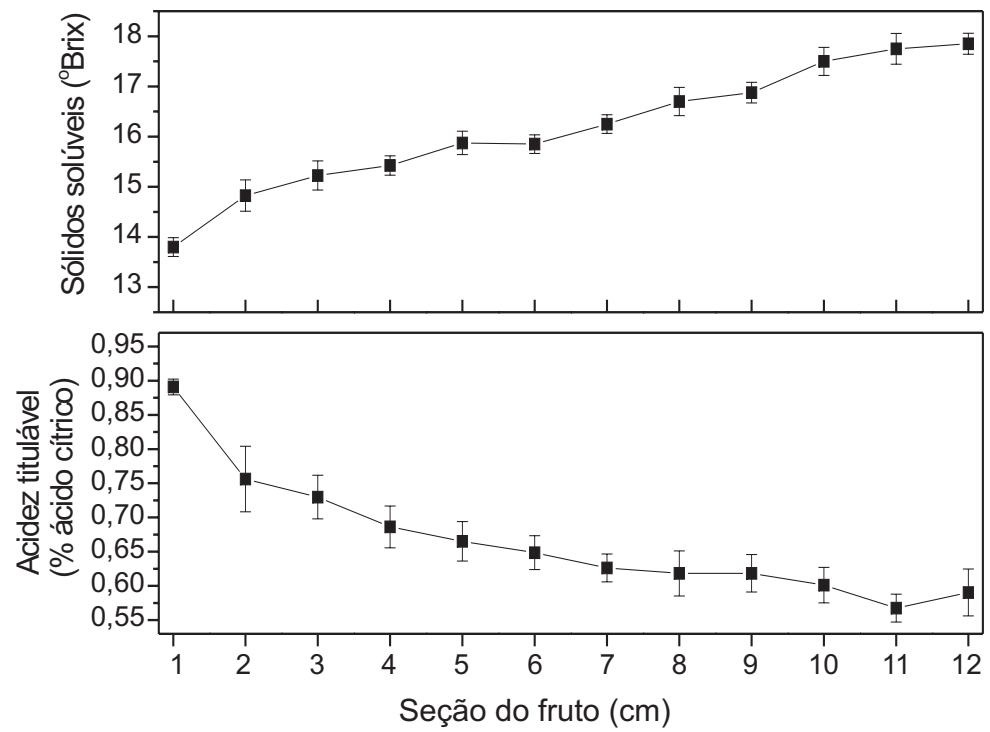

FIGURA 1 - Sólidos solúveis ( ${ }^{\circ}$ Brix) (A) e acidez titulável (\% ácido cítrico) (B) em abacaxis 'Pérola'. DMS = diferença mínima significativa $(\mathrm{p} \leq 0,05)$.
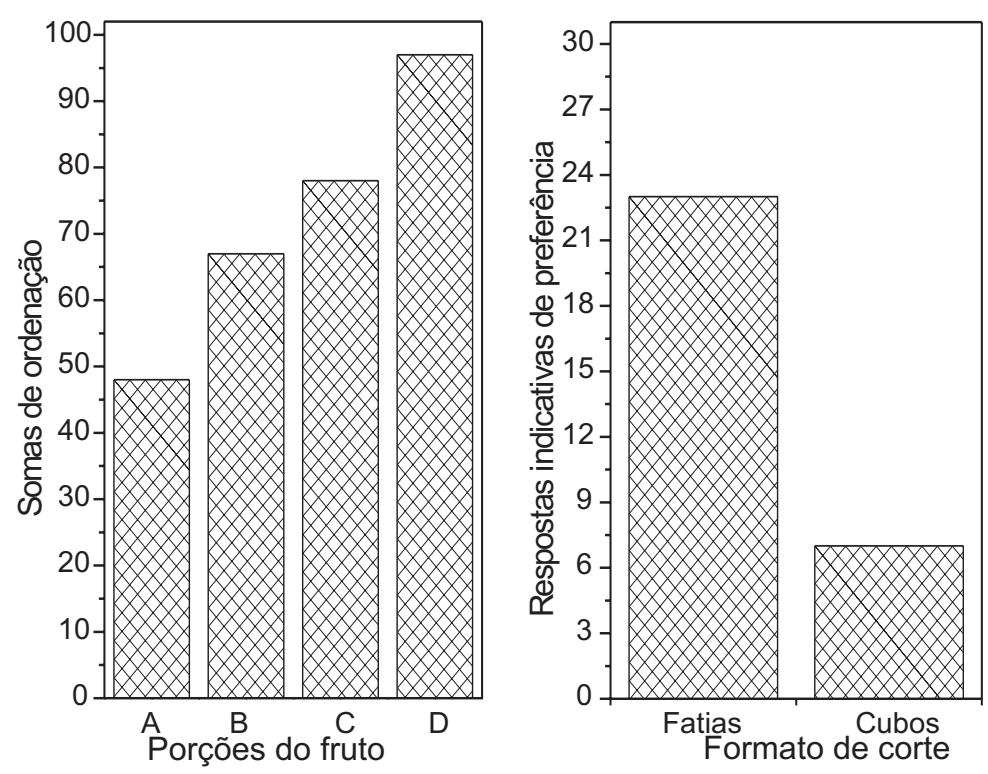

FIGURA 2 - Testes de Ordenação-Preferência quanto às diferentes porções do abacaxi (A) e de Preferência-Pareada quanto ao formato de corte preferido (B).

Os teores de SS e AT mantiveram-se na faixa estabelecida por Kader (1999) e, portanto, não haveria restrições quanto à utilização de todas as seções do fruto no processamento mínimo. No entanto, sensorialmente, a porção delimitada pelos 3 centímetros apicais foi pouco aceita, sugerindo que a porção compreendida entre a $4^{\mathrm{a}}$ e a $12^{\mathrm{a}}$ seções seja preferencialmente utilizada no processamento mínimo e que, existindo a possibilidade, a porção apical seja redirecionada para qualquer outro processo industrial, como o preparo de suco, polpa, geléia, abacaxi em calda ou abacaxi desidratado. A preferência pela porção basal do fruto está diretamente relacionada aos maiores teores de açúcares, representados pelos sólidos solúveis, e menores de acidez, que caracterizam o grau de maturação do fruto. O acúmulo de sólidos solúveis acompanha o gradiente de maturação dos frutos da região basal para a apical, ao passo que a acidez é sempre maior na região apical em função do estádio de maturação menos avançado dos frutilhos 
situados nesta porção.

No teste de preferência para tipo de corte, 23 das 30 respostas indicaram a fatia como o formato de corte preferido. Considerando que este valor é superior ao número mínimo tabelado de respostas corretas para se estabelecer diferença significativa a $5 \%$ de probabilidade (21), conclui-se que houve preferência significativa do corte no formato de fatias em relação ao em cubos (Figura $2 \mathrm{~B}$ ). As justificativas pela preferência das fatias foram a menor manipulação no preparo do produto e o formato mais próximo ao do fruto in natura; já os julgadores que preferiram o corte em cubos, fizeram-no em função da praticidade para consumo, sugerindo, inclusive, que o tamanho dos cubos fosse reduzido. Mesmo preferindo o corte em fatias, 2 julgadores comentaram que ambos os tipos de corte seriam bem aceitos, por atenderem a necessidades diferentes do mercado consumidor.

\section{AGRADECIMENTOS}

À Fundação de Amparo à Pesquisa do Estado de São Paulo (FAPESP), pelo apoio financeiro. À Embrapa - Centro Nacional de Pesquisa de Agroindústria Tropical, pelo suporte físico. À Claísa A. Silva de Freitas, pelo auxílio na instalação e avaliação do experimento.

\section{REFERÊNCIAS}

AGRIANUAL 2005: anuário da agricultura brasileira. São Paulo: FNP Consultoria \& Agroinformativos, 2005. p.167-174.

BOTREL, N.; PATTO DE ABREU, C.M. Colheita, cuidados e fisiologia pós-colheita do abacaxi. Informe Agropecuário, Belo Horizonte, v.17, n.179, p.33-40, 1994.

DULL, G.G. The pineapple: general. In: HULME,A.C. The biochemistry of fruits and their products. London: Academic Press, 1971. v.2, cap. 9A, p.303-324.
FERREIRA, V.L.P. et al. Análise sensorial: testes discriminativos e afetivos. Campinas-SP: Sociedade Brasileira de Ciência e Tecnologia de Alimentos, 2000. 127p. (Manual: Série Qualidade).

GONÇALVES, N.B. Abacaxi: pós-colheita. Brasília: Embrapa - SCT, 2000. 45p. (Frutas do Brasil, 5).

KADER. A. A. Pineapple. Disponível em: <http:// postharvest.ucdavis.edu/Produce/ produceFacts /index.html $>$. Acesso em: 19 nov. 1999.

REINHARDT, D.H.; MEDINA, V.M.; CALDAS, R.C.; ALVES, A.A. Gradientes de qualidade e metodologia de amostragem para análise de frutos de abacaxi 'Pérola'. Cruz das Almas-BA: Embrapa Mandioca e Fruticultura, 2003. 4p. (Comunicado Técnico, 90).

SARZI, B.; DURIGAN, J.F.; ROSSI JR., O.D. Temperatura e tipo de preparo na conservação de produto minimamente processado de abacaxi 'Pérola'. Revista Brasileira de Fruticultura, Jaboticabal, v.24, n.2, p.376-380, 2002.

SIRIPHANICH, J.; JOHNSON, G.I. Minimal processing of tropical fruits. ACIAR Proceedings, v.50, p.127-137, 1994.

SMITH, L.G. Indices of physiological maturity and eating quality in Smooth Cayenne pineapples. 2. Indices of eating quality. Queensland Journal of Agricultural and Animal Sciences, Brisbane, v.45, n.2, p.219-228, 1988.

USBERTI FILHO, J.A.; SIQUEIRA, W.J.; SPIRONELLO, A.; TANAKA, M.A.S.; SIGRIST, J.M.M.; MARTINS, A.L.M.; BORTOLETTO N.; TSUHAKO, A.T.; GUSHIKEN, A. Abacaxi gomo-de-mel. Campinas: Instituto Agronômico, 1999. 5p. Disponível em: <http:// 200.136.175.13/homeiac/produtos/abacaxi.htm $>$. Acesso em: 19 nov. 1999. 